\title{
DISTRIBUSI DAN KELIMPAHAN KEPITING BAKAU (Scylla sp.) DI PERAIRAN MUARA SUNGAI CENRANAE KABUPATEN BONE
}

\author{
Gunarto $^{*}$, Rohama Daud*), Suwardi ${ }^{*}$ dan Adi Hanafi ${ }^{*}$
}

\begin{abstract}
ABSTRAK
Penelitian bertujuan untuk mengetahui distribusi dan kelimpahan kepiting bakau (Scylla sp.) di perairan Muara Sungai Cenranae, Kabupaten Bone, Sulawesi Selatan. Tiga lokasi penghasil kepiting di perairan Muara Sungai Cenranae, yaitu Latonro, Pallime, dan Pusunge ditentukan sebagai tempat untuk penelitian. Peubah biologi yang diamati adalah bobot kepiting hasil tangkapan nelayan di lokasi tersebut. Data penunjang yang diamati adalah kualitas air yang meliputi salinitas. $\mathrm{pH}$ dan suhu air.

Data yang diperoleh menunjukkan bahwa di ketiga tempat tersebut hasil tangkapan kepiting terbagi atas tiga kelas, yaitu kepiting ukuran 20.60 g mencapai $80 \%$ (Latonro), 86.5\% (Pallime), dan 75\% (Pusunge). Kepiting ukuran 61.150 g. yaitu 16.2\% (Latonro). 10.6\% (Pallime), dan 18.9\% (Pusunge). Sedangkan kepiting yang berukuran lebih dari $150 \mathrm{~g}$ jumlahnya sedikit, yaitu $3.8 \%$ (Latomro). 2.9\% (Pallime), dan 6.1\% (Pusunge). Hasil pengamatan kelimpahan benih kepiting yang ditangkap dengan seser pada bulan Agustus dan September 1997. menunjukkan jumlah tangkapan tertinggi terjadi pada bulan September $\left(63 \mathrm{ind} / 250 \mathrm{~m}^{2}\right)$, yaitu pada lokasi Pusunge dan didominasi oleh kepiting ukuran 5-30 g. Hasil pengamatan terhadap salinitas pada periode JuniJuli 1997 menunjukkan kisaran 2.10 ppt (Latonro), 1-10 ppt (Pallime), dan 10.15 ppt (Pusunge), pH 7,5-8.0 dan suhu air berkisar antara $28 \cdot 30^{\circ} \mathrm{C}$ untuk ketiga lokasi.
\end{abstract}

\section{ABSTRACTS: Distribution and abundances of mangrove crab (Scylla sp.) at the Cenranae Estuarine Bone Regency. By: Gunarto, Rohama Daud, Suwardi and Adi Hanafi}

\begin{abstract}
A study uas condurted to observe the distribution and abundance of mangrove (rab (Srylla sp.) at the Cenranae estuarine Bone Regency South Sulawesi. Mangrove crab catches by fishermen were monitored at three areas (Pallime, Latonro and Pusunge). The biological data collected were carapace length and body weight. Water quality parameters including salinity, pH and temperature were recorded.

The total crab catche's in pach area was divided into three size categories i.e. 20-60, 61-150 and $>150 \mathrm{~g}$. Crab catches represented by the first size category was 80\% (Latonro), 86,5\% (Pallime) and $75 \%$ (Pusunge), the second category was 16,2\% (Latonro), 10,6\% (Pallime) and 18,9\% (Pusunge), and the third category was 3,8\% (Latonro); $2.9 \%$ (Pallime) and 6,1\% (Pusunge). The other gear method which used scope net "seser" showed that the highest crab catches on September (63 $\left(\mathrm{rab} / 250 \mathrm{~m}^{2}\right)$ at the Pusinge waters was dominated by crab size of 5-30 g. The salinity fluctuation at June to July 1997 attained 2.10 ppt (Latonro), 1-10 ppt (Pallime) and 10-15 ppt (Pusunge), pH and water temperature attained $7.5-8$ and $28-30^{\circ} \mathrm{C}$ respectively.
\end{abstract}

KEYWORDS: Distribution; abundances; mangrove crab; Cenranae estuarine.

\section{PENDAHULUAN}

Kepiting bakau merupakan satu di antara komoditas perikanan yang mempunyai nilai ekonomis cukup baik di kawasan Asia Tenggara dan Selatan (Chandrasekaran dan Natarajan.
1994) serta di Australia (Heasman et al., 1985). Sampai saat ini budidaya kepiting bakau baik budidaya penggemukan maupun pembesaran telah dilakukan di tambak-tambak rakyat di Indonesia misalnya di Bone Sulawesi Selatan dan Cilacap, Jawa Tengah (Cholik dan Hanafi, 1991).

") Peneliti pada Balai Penelitian Perikanan Pantai. Maros. 
Sedangkan di Thailand budidaya kepiting bakau telah berkembang di propinsi Surat Thani dan Chonburi (Prinpanapong dan Youngwani-chsacd, 1991).

Usaha budidaya lebih berkembang dengan dijadikannya Kabupaten Bone sebagai pusat pengembangan budidaya kepiting bakau di Sulawesi Selatan dengan wilayah pengembangannya Kabupaten Luwu, Sinjai dan Wajo (Anonimus, 1996), maka jelas kebutuhan benih kepiting akan semakin meningkat. Kebutuhan ini belum bisa dipenuhi melalui panti benih, karena teknologi perbenihannya belum berhasil dengan baik. Kematian di tingkat zoea yang tinggi dan kanibalisme menyebabkan rendahnya tingkat sintasan zoea kepiting bakau untuk mencapai stadia megalopa atau kepiting muda (Marichamy dan Rajapackiam, 1991; Yunus, 1992).

Perairan Muara Sungai Cenranae di Kabupaten Bone, merupakan daerah mangrove yang padat ditumbuhi pohon nipah (Nypha sp.), dan aliran air sungai banyak mengandung muatan lumpur yang berasal dari daerah hulu dan diendapkan di daerah muara sehingga terlihat terjadi pendangkalan di daerah tersebut. Dengan demikian di daerah muara menjadi perairan yang subur dan hal ini ditandai dengan banyaknya spat tiram Crassostrea sp. tumbuh di pangkal batang pohon nipah sedang di dasar substrat perairan banyak tumbuh kekerangan seperti Lithophaga sp. Dengan sumber air tawar yang cukup besar yang berasal dari Danau Tempe, maka keadaan fluktuasi salinitas di daerah Muara Sungai Cenranae cukup besar dan jelas perbedaannya antara pada saat air pasang maupun pada waktu air surut. Dengan faktor-faktor di atas, maka kemungkinan daerah tersebut sangat cocok sebagai nursery ground benih kepiting bakau.

Dengan berkembangnya budidaya kepiting maka kebutuhan benih akan semakin meningkat. Untuk memenuhi kebutuhan benih kepiting tersebut, maka penangkapan di alam dilakukan secara intensif, seperti yang sedang terjadi di daerah Muara Sungai Cenranae, Kabupaten Bone Sulawesi Selatan. Usaha penangkapan sangat dibatasi oleh populasinya di alam, sehingga aktivitasnya harus mempertimbangkan keberlanjutan populasinya di alam. Penelitian ini bertujuan untuk mengetahui distribusi dan kelimpahan kepiting bakau di daerah Muara Sungai Cenranae, Kabupaten Bone.

\section{METODE}

Penelitian dilaksanakan di daerah Muara Sungai Cenranae dengan menentukan 3 lokasi, yaitu Perairan Pallime, Latonro dan Pusunge (Gambar 1), dengan cara memonitor jumlah dan ukuran (panjang karapas dan bobot) kepiting bakau hasil tangkapan oleh nelayan. Penangkapan kepiting bakau oleh nelayan dilakukan dengan menggunakan "rakkang" masing-masing berjumlah 40 buah. Penangkapan umumnya dilakukan pada waktu air laut mulai pasang sampai mencapai puncak pasang (lebih kurang 4-5 jam/ hari). Sedangkan lokasi penangkapan secara tepat diperoleh melalui wawancara dengan nelayan yang dijadikan enumerator dan mengadakan pengamatan secara langsung di areal penangkapan, kemudian hasil pengamatan dan wawancara diplotkan ke dalam peta. Data bobot kepiting kemudian ditabulasi untuk melihat struktur ukuran kepiting hasil tangkapan. Setiap dua minggu antara Mei-Juli 1997, diukur parameter kualitas air yang meliputi salinitas, $\mathrm{pH}$ dan suhu air, BOT, $\mathrm{NO}_{3}$, dan $\mathrm{PO}_{4}$

Untuk melihat kelimpahan kepiting bakau di perairan Muara Sungai Cenranae, dilakukan sampling kelimpahan dengan cara swept area yang menggunakan alat tangkap seser dengan ukuran panjang $3 \mathrm{~m}$ dan lebar bukaan mulut 2,5 $m$. Alat tangkap tersebut digunakan dengan cara didorong masuk ke dalam tanah $( \pm 5.10 \mathrm{~cm})$ terlebih dahulu, kemudian didorong ke depan sejauh $50 \mathrm{~m}$ dan di ulang 2 kali. Dengan demikian area sapuan pada setiap lokasi seluas $(50 \mathrm{~m} \times 2,5 \mathrm{~m}) \times 2=250 \mathrm{~m}^{2}$. Tiga stasiun daerah sampling ditentukan, yaitu: 1) Muara Sungai Capitengae yang masuk dalam wilayah Desa Pusunge, 2). Muara Sungai Latonro yang masuk wilayah Desa Latonro, dan 3) Aliran Sungai Cenranae di daerah Pallime. Kepiting hasil tangkapan dihitung dan diukur lebar karapas. nya. Beberapa parameter kualitas air yang diukur setiap 2 minggu (Agustus-September, 1997), yaitu salinitas, $\mathrm{pH}, \mathrm{BOT}, \mathrm{NO}_{3}$, dan $\mathrm{PO}_{4}$.

\section{HASIL DAN DISKUSI}

Hasil tangkapan kepiting oleh nelayan selama dua bulan (Juni-Juli 97) dapat dilihat pada Tabel 1. Dari data bobot kepiting hasil tangkapan di ketiga lokasi terlihat struktur ukurannya tidak banyak berbeda, didominasi oleh ukuran 20-60 g, yaitu sebanyak $86,5 \%$ (Pallime), $80 \%$ (Latonro) 


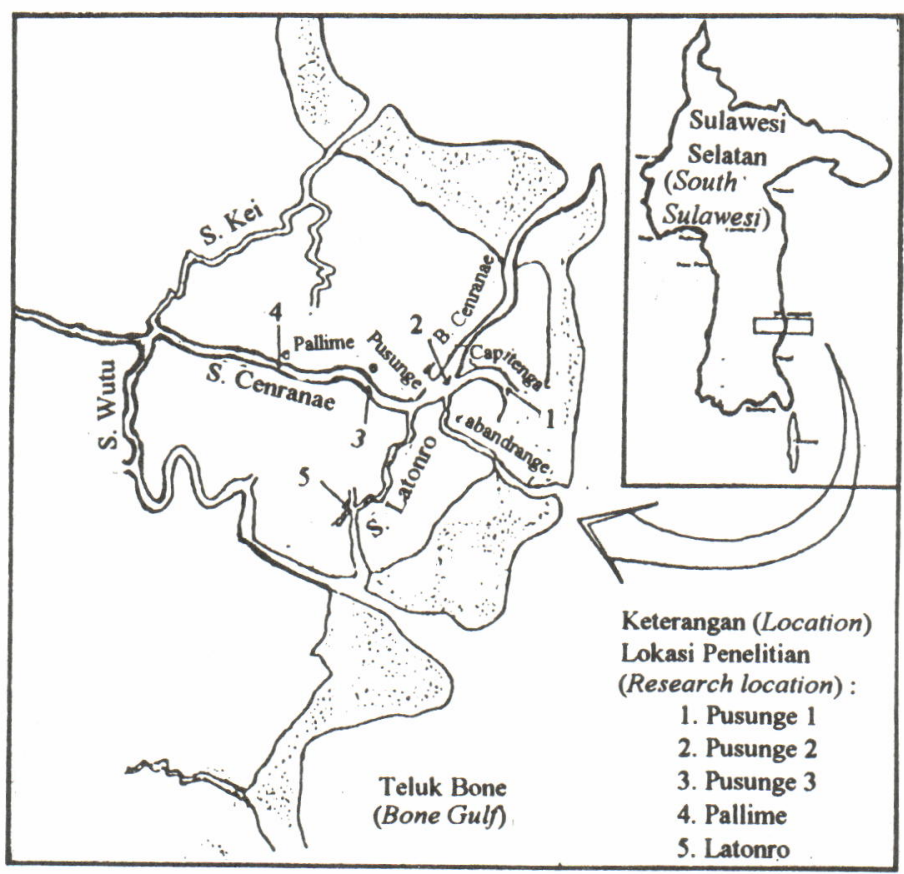

Gambar 1. Peta Muara Sungai Cenranae dengan lokasi penelitian.

Figure 1. The map of Cenranae estuarine showing the study sites.

dan 75\% (Pusunge). Di Pichavaram mangrove India, ukuran kepiting yang tertangkap dengan trap net dan jala didominasi oleh ukuran 20-30 g, yaitu mencapai $48 \%$ dari total hasil tangkapan. Ukuran kepiting yang paling besar tertangkap dengan "rakkang" pada periode Juni-Juli 1997 adalah antara 150-200 g dan jumlahnya cukup sedikit, yaitu sebanyak 2,9\% (Pallime), 3,8\% (Latonro) dan 6,1\% (Pusunge). Dengan demikian terdapat gambaran nyata bahwa jumlah individu cenderung menurun dengan meningkatnya ukuran bobot kepiting. Hal ini berbeda dengan hasil tangkapan kepiting di Muara Sungai Tamuku Bone-Bone, Kabupaten Luwu, ukuran kepiting bakau yang tertangkap pada kisaran bobot 120-650 g (Mallawa, 1991). Di perairan mangrove Segara Anakan, Cilacap pada tahun 1986, dari 3739 individu kepiting bakau yang ditangkap dengan wadong didominasi oleh ukuran 100-200 g, yaitu sebanyak 60,01\%. Ukuran kurang dari 100 g sebanyak 12,36\%. Sedangkan yang berukuran 201-400 g dan 401600 g, masing-masing sebanyak 23,96\% dan $3,26 \%$. Sedangkan sisanya $(0,43 \%)$ adalah kepiting yang berukuran bobot 600-1300 g ('Toro,
1986). Dengan demikian ternyata struktur ukuran kepiting bakau yang tertangkap di perairan mangrove di Sungai Cenranae, Kabupaten Bone lebih kecil dari pada di perairan mangrove Segara Anakan Cilacap. Hal ini kemungkinan karena perbedaan tipe habitat mangrove yang digunakan sebagai tempat menangkap kepiting bakau, di mana di Segara Anakan areal penangkapan dilakukan di laut, sedangkan di Muara Sungai Cenranae lokasi penangkapan berada di sebelah dalam Muara Sungai. Burke et al. (1982) menyatakan bahwa kepiting ukuran panjang karapas antara 20-60 $\mathrm{mm}$ berada di sekitar perairan mangrove baik pada waktu air pasang maupun surut. Sedangkan kepiting dengan panjang karapas berukuran 70-150 mm berada di perairan mangrove hanya pada saat air pasang, sedangkan apabila air surut kepiting ukuran tersebut akan masuk kembali ke laut. Hal ini telah terbukti dengan hasil tangkapan kepiting dengan rakkang di Muara Sungai Cenranae, Kabupaten Bone yang didominasi oleh ukuran panjang karapas antara 20-60 mm $(>75 \%)$, sedangkan ukuran yang lebih besar dari $60 \mathrm{~mm}$ jumlahnya cukup sedikit $(<25 \%)$. 


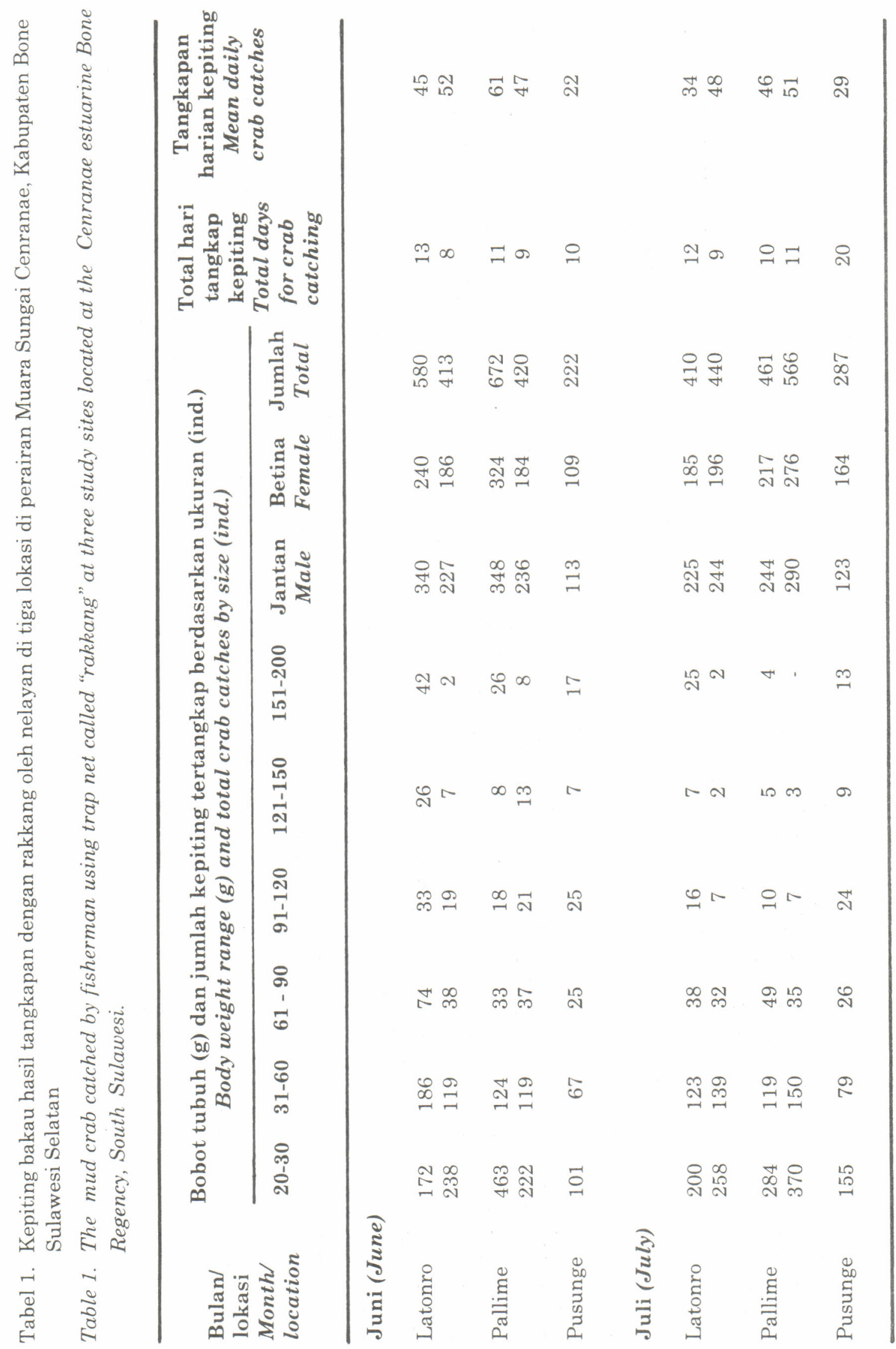


Dari hasil tangkapan tersebut telah membuktikan bahwa perairan mangrove adalah sebagai tempat mencari makan ("nursery area") kepiting bakau muda yang didominasi ukuran panjang karapas 20-60 mm (ukuran benih). Burke et al, (1982) mengatakan bahwa larva kepiting bakau setelah mencapai fase megalopa, maka akan segera masuk ke perairan mangrove untuk mencari makan dan selanjutnya tumbuh di daerah mangrove sampai ukuran tertentu dan akan kembali masuk ke laut.

Alat tangkap lain yang digunakan untuk melihat kelimpahan kepiting bakau adalah "seser". Hasil tangkapan kepiting bakau dengan menggunakan "seser" dapat dilihat pada Tabel 2.

Pada Tabel 2 dapat dilihat bahwa hasil tangkapan kepiting dengan menggunakan seser di perairan Muara Capitengae yang masuk wilayah Desa Pusunge (Pusunge 1, Pusunge 2 dan Pusunge 3) didominasi oleh ukuran kepiting 5-30 g, di mana pada bulan September (126 individu) lebih banyak hasil tangkapan dibanding dengan pada bulan Agustus 97 (23 individu). Dengan demikian kepadatan benih kepiting di Pusunge pada bulan Agustus 1997 adalah 7 individu $/ 250 \mathrm{~m}^{2}$ dan pada bulan September 1997 adalah 63 individu $/ \mathrm{m}^{2}$. Sedangkan kepiting yang tertangkap di Latonro dan Pallime ukurannya cenderung lebih besar dari pada yang tertangkap di Pusunge, walaupun jumlahnya cukup sedikit, yaitu pada bulan Agustus dan September masingmasing dengan kepadatan 6 individu/250 $\mathrm{m}^{2}$ dan di Latonro 3 individu $/ 250 \mathrm{~m}^{2}$. Sebagai pembanding, kelimpahan kepiting bakau ukuran $>150 \mathrm{~g}$ di perairan mangrove Maryborough Queensland, Australia sebanyak 6,9 individu/ha (Burke et al., 1982). Apabila hal ini dikaitkan dengan letak lokasi sampling dengan mulut muara, maka sampling yang dilakukan di perairan Pusunge $1 \mathrm{mem}$-punyai jarak yang paling dekat ke mulut muara/laut $( \pm 100 \mathrm{~m})$, sedangkan di perairan Pusunge 2 lebih kurang $1000 \mathrm{~m}$ dan di Pallime lebih kurang $3000 \mathrm{~m}$ dari mulut Muara Babana Cenranae (Gambar 1).

Tabel 2. Jumlah kepiting bakau Scylla sp. hasil tangkapan dengan "seser" di beberapa lokasi di perairan Muara Sungai Cenranae, Kabupaten Bone.

Tabel 2. Total mud crab Scylla sp. catched by scoop net at different location of Cenranae estuarine Bone Regency.

\begin{tabular}{|c|c|c|c|c|c|c|c|c|}
\hline \multirow[t]{2}{*}{$\begin{array}{l}\text { Bulan/lokasi } \\
\text { Month/ } \\
\text { location }\end{array}$} & \multicolumn{7}{|c|}{$\begin{array}{l}\text { Bobot tubuh (g) dan jumlah tangkapan kepiting menurut } \\
\text { ukuran (ind.) } \\
\text { Body weight ranges (g) and total crab catches by size (ind.) }\end{array}$} & \multirow[t]{2}{*}{$\begin{array}{l}\text { Salinitas } \\
\text { Salinity } \\
\text { (ppt) }\end{array}$} \\
\hline & $5-30$ & $31-60$ & $61-90$ & $>90$ & $\begin{array}{r}\text { Jantan } \\
\text { Male }\end{array}$ & $\begin{array}{l}\text { Betina } \\
\text { Female }\end{array}$ & $\begin{array}{c}\text { Jumlah } \\
\text { Total }\end{array}$ & \\
\hline
\end{tabular}

Agustus '97 (August '97)

Pusunge I 9

Pusunge II

Pusunge III

Pallime

Latonro

\section{September ' 97}

Pusunge I

60

Pusunge II

66
1

1

4

3

$\begin{array}{llll}- & 10 & 25 \\ 1 & 2 & 11 & 20 \\ & 2 & 3 & 20 \\ 1 & 6 & 10 \\ 1 & 3 & 15\end{array}$

25

20

20

10

15

Pallime 2 28 
Gunarto, Daud, R., Suwardi dan Hanafi A.

Sampling kelimpahan juga dilakukan di perairan Latonro yang letaknya tidak satu aliran utama di Sungai Cenranae, tetapi masuk ke aliran anakan sungainya. Hal ini dipilih karena anakan Sungai Latonro dipengaruhi oleh dua sungai besar, yaitu Sungai Cenranae dan Sungai Watu. Data salinitas menunjukkan bahwa pada salinitas yang lebih rendah 10-15 ppt seperti di Pallime dan Latonro, justru tertangkap benih kepiting yang berukuran lebih besar. Belum diketahui apakah hal ini ada kaitan dengan usaha kepiting untuk bermigrasi ke perairan dengan salinitas yang lebih rendah untuk mendapatkan laju tumbuh yang optimal. Gunarto et al. (1987), mendapatkan kepiting bakau juvenil tumbuh baik pada salinitas 10-15 ppt. Sedangkan pada lokasi dengan salinitas yang lebih tinggi (20-30 ppt), banyak tertangkap kepiting yang ukuran panjang karapasnya lebih kecil $(28,18-33,95 \mathrm{~mm})$ dan jumlahnya lebih banyak. Hal ini kemungkinan kepiting pada ukuran tersebut masih memerlukan salinitas yang lebih tinggi untuk pertumbuhannya. La Sara (1994) menyatakan bahwa perbedaan kelimpahan kepiting bakau disebabkan oleh kedalaman air dan ketersediaan pakan alami di perairan. Namun demikian Hill (1980) menyatakan bahwa kepiting bakau cenderung mencari pakan pada kondisi perairan yang dangkal. Jenis pakan yang disukai kepiting bakau adalah organisme benthos yang bergerak lambat, seperti siput dan kekerangan, krustasea, serasah dan perakaran tumbuhan mangrove. Dari data makrozoobenthos yang diamati ternyata di perairan Muara Sungai Cạpitengae (Pusunge 1 dan 2) banyak dijumpai jenis kerang Lithophaga sp. yang dimanfaatkan sebagai sumber makanannya. Data kualitas air pada bulan Juni dan Juli 1997, dapat dilihat pada Tabel 3.

Dari Tabel 3, dapat dilihat bahwa salinitas di Muara Sungai Cenranae berfluktuasi dan sangat dipengaruhi oleh kondisi air pasang dari laut dan aliran air tawar yang berasal dari danau Tempe. Salinitas pada bulan Juni-Juli dimana sedang berlangsung musim hujan, fluktuasi salinitas yang terjadi pada waktu pasang dan surut cukup tinggi. Dari ketiga lokasi penelitian salinitas masing-masing, yaitu antara 1-10 ppt (Pallime), 2-10 ppt (Pusunge) dan 10-15 ppt (Pusunge). Sedangkan pada bulan Agustus kisaran salinitas menjadi 5-20 ppt (Pallime), 5-25 ppt (Latonro) dan 20-30 ppt (Pusunge1 dan 2).

Keasaman $(\mathrm{pH})$ di ketiga, yaitu pada waktu air pasang $\mathrm{pH}$ 7,50 (Pallime), 7,50 (Latonro) dan 7,55 (Pusunge). Di mangrove Segara Anakan Cilacap $\mathrm{pH}$ rata-rata pada saat air surut adalah 7,04 dan pada waktu air pasang 7,18 (La Sara, 1994). Sedangkan menurut Toro, (1987) kepiting bakau hidup pada $\mathrm{pH} 6,16-8,9$. Kandungan bahan organik total (BOT) makin ke muara (Pusunge) cenderung makin tinggi berbanding dengan di dua lokasi lainnya, yaitu mencapai nilai 46,45 ppm yang terjadi pada bulan September. Hal ini menunjukkan bahwa pada bulan tersebut perairan telah menjadi sangat subur (Tabel 2). Kenyataan ini ditandai dengan melimpahnya jenis kerang Lithophaga sp. dengan kepadatan 300-400 individu/ $20 \mathrm{~cm}^{2}$ terutama di perairan Pusunge. Faktor inilah yang kemungkinan menyebabkan di perairan Pusunge lebih banyak ditangkap benih kepiting yang berukuran lebih kecil dibanding dengan di perairan Pallime dan

Tabel 3. Kisaran parameter kualitas air di muara sungai Cenranae selama penelitian

Tabel 3. Water quality parameter at the Cenranae estuarine during the study.

\begin{tabular}{lccccc}
\hline $\begin{array}{l}\text { Lokasi } \\
\text { Location }\end{array}$ & \multicolumn{5}{c}{ Peubah kualitas air (Water quality parameters) } \\
\cline { 2 - 6 } & $\begin{array}{c}\text { Salinitas } \\
\text { Salinity (ppt) }\end{array}$ & $\mathbf{p H}$ & $\begin{array}{c}\text { BOT } \\
\text { TOM (ppm) }\end{array}$ & $\begin{array}{c}\mathbf{N O}_{3} \\
(\mathbf{p p m})\end{array}$ & $\begin{array}{c}\mathbf{P O}_{4} \\
\mathbf{( p p m )}\end{array}$ \\
\hline 1. Pallime & $1-10$ & $7,06-7,70$ & $5,31-27,87$ & $0,06-0,03$ & $0,32-0,47$ \\
2. Latonro & $2-10$ & $7,49-7,85$ & $6,64-33,18$ & $0,04-0,15$ & $0,26-0,42$ \\
3. Pusunge & $10-15$ & $7,55-7,99$ & $13,27-46,45$ & $0,02-0,41$ & $0,26-0,58$ \\
\hline
\end{tabular}


Latonro (Tabel 3). Sedangkan kandungan nitrat dan fosfat di perairan Muara Sungai Cenranae dijumpai dari cukup rendah sampai cukup tinggi, yaitu antara 0.02-0,03 ppm (Pallime), 0,26-0,42 ppm (Latonro) dan 0,26-0,58 ppm (Pusunge). Perkin 1974 dalam Atmomarsono, 1983 mengatakan bahwa kandungan fosfat terlarut di. perairan alami tidak lebih dari $0,1 \mathrm{ppm}$, kecuali pada perairan penerima limbah rumah tangga dan pertanian. Data tersebut menunjukkan bahwa pertambakan dan limbah rumah tangga di sekitar Muara Sungai Cenranae cukup besar pengaruhnya terhadap sumbangan fosfat dalam perairan tersebut.

\section{KESIMPULAN}

- Kepiting bakau di Muara Sungai Cenranae distribusinya tersebar luas ke seluruh anakan sungainya, namun terdapat pula beberapa daerah konsentrasi benih kepiting misalnya di Muara Capitengae yang masuk wilayah Desa Pusunge ( Pusunge 1, 2).

- Kelimpahan kepiting di Muara Capitengae (Pusunge) pada periode Agustus-September 1997 mencapai $7-63$ individu $/ 250 \mathrm{~m}^{2}$. Hal ini terlihat paling banyak dibandingkan dengan di lokasi lainnya misalnya Muara Sungai Latonro dan perairan Pallime, namun demikian ukuran kepiting yang tertangkap di Muara Capitengae jauh lebih kecil daripada yang tertangkap di perairan Latonro dan Pusunge. Hal ini kemungkinan karena perbedaan kadar garam yang diperlukan untuk kehidupan kepiting.

Struktur populasi kepiting hasil tangkapan dengan "rakkang" di Muara Sungai Cenranae (Pusunge, Pallime dan Latonro) didominasi oleh ukuran 20-60 g (75-86,5\%), sedangkan yang berukuran $61-150 \mathrm{~g}$ antara $10,6-18,9 \%$ dan yang berukuran 151-200 g sebanyak 2,9$6,1 \%$.

\section{UCAPAN TERIMA KASIH}

Penulis mengucapkan banyak terima kasih kepada analis (A. Muhammad Sabir, Sutrisyani, dan Rifka Pasande) yang telah membantu dalam terlaksananya penelitian ini.

\section{DAFTAR PUSTAKA}

Anonimus. 1996. Pusat pengembangan produksi kepiting Sulawesi Selatan. Pemerintah Propinsi Dati I Sulawesi Selatan. 15 p.

Atmomarsono, M. 1983. Studi kasus kualitas perairan tambak di Kecamatan Pedes, Kabupaten Karawang, Jawa Barat. Skripsi pada Fakultas Peternakan Jurusan Perikanan Universitas Diponegoro 105 hal.

Burke, J.B.; N.C. Cillespie; B. J. Hill; S. J. Hyland and M. J. Williams. 1982. The Quensland mud crab fishery. B. J. Hill, eds. Fishery Research Branch Qld. Department of Primary Industries. PO Box 344 Queensland, Australia.

Cholik, F. and A. Hanafi. 1991. A review of the status of the mud crab (Scylla sp.) fishery and culture in Indonesia. The Mud Crab, A report on the seminar convened in SuratThani, Thailand, November 5-8, 1991. pp : 13-28.

Chandrasekaran V.S. and R. Natarajan. 1994. Seasonal abundance and distribution of seeds of mud crab Scylla serrata in Pichavaram mangrove Southeast India. J. Aqua Trop 9 : 343-350.

Gunarto; A. Mustafa; dan Suharyanto. 1987. Pemeliharaan kepiting bakau Scylla serrata (Forskal) pada berbagai tingkat kadar garam dalam kondisi laboratorium. J. Pen. Bud. Pantai 3 (2) : 60-64.

Hill, B.J. 1980. Effects of temperature on feeding and activity in the activity crab Scylla serrata. Mar. Biol. 59 : 189-192.

Heasman, M.P.; D.R. Fielder; and R.K. Stepherd. 1985. Mating and spawning in the mud crab, Scylla serrata (Forskal) (Decapoda: Portunidae) in Morton Bay, Queensland. Aus. J Mar. Freshw. Res. (36) : 773-783.

La sara. 1994. Hubungan kelimpahan kepiting bakau, Scylla sp. dengan kualitas habitat di perairan Segara Anakan, Cilacap. Thesis Program Pasca Sarjana Institut Pertanian Bogor. $75 \mathrm{p}$.

Marichamy, R. and Rajapackiam. 1991. Experiment on larval rearing and seed production of the mud crab Scylla serrata (Forskal). The Mud Crab, A report on the seminar convened in SuratThani, Thailand, November 5-8, 1991. 
Mallawa, A. 1991. Penggunaan bubu piramid dalam penangkapan kepiting bakau Scylla serrata. Torani. Bulletin Ilmu dan Teknologi Kelautan Universitas Hasanuddin Ujung Pandang, pp : 30 - 37.

Pripanapong, S. and T. Youngwanichsaed. 1991. Rearing of mud crab Scylla serrata.The Mud Crab, A report on the seminar convened in SuratThani, Thailand, November 5-8, 1991. pp.
Toro, A.V. 1986. Ekologi kepiting bakau niaga Scylla serrata Forskal di perairan mangrove Segara Anakan, Cilacap, Jawa Tengah. Seminar III Ekosistem Mangrove, Denpasar Bali 5-8 Agustus 1986. pp : 147-155.

Yunus. 1992. Pemeliharaan larva kepiting bakau Scylla serrata dengan beda kepadatan rotifera Brachionus plicatilis. J. Pen. Bud. Pantai 8 (2): 9-14. 